\title{
Concerted Induction of the S3 Alkylsulphatase of Pseudomonas C12B by Combinations of Alkyl Sulphates and Alcohols
}

\author{
By PATRICIA G. M. HUMPHREYS, $\dagger$ DUNCAN J. SHAW \\ KENNETH S. DODGSON AND GRAHAM F. WHITE* \\ Department of Biochemistry, University College Cardiff, PO Box 78, Cardiff CF1 1XL, UK
}

(Received 7 June 1985; revised 2 October 1985)

Growth of the detergent-degrading bacterium Pseudomonas $\mathrm{C} 12 \mathrm{~B}$ on pyruvate supplemented with pure tetradecan-2-sulphate and tetradecan-2-ol together, led to induction of the S3 alkylsulphatase active towards symmetrical or near-symmetrical secondary alkyl sulphates. Induction was accompanied by disappearance of the tetradecan-2-sulphate surfactant and by the appearance of some of the S 3 activity (up to $45 \%$ of the total) in the culture fluid. Induction did not occur when one or other or both of the $\mathrm{C}_{14}$ compounds was omitted from the minimalpyruvate growth medium, nor with resting cell suspensions even with both compounds present. Provided that the pyruvate medium contained tetradecan-2-sulphate, good induction of S3 enzyme could also be achieved by replacing tetradecan-2-ol with any one of most secondary alcohols tested, including alkan-2-ols $\left(C_{4}\right.$ to $\left.C_{16}\right)$, symmetrical alcohols $\left(C_{5}\right.$ to $\left.C_{13}\right)$ and decanol isomers with the hydroxyl at C-3, C-4 or C-5. Primary alcohols were ineffective. Requirements for the ester component of the inducer combination were more closely defined; maintaining tetradecan-2-ol and pyruvate as constant components, no activity was detected with $\mathrm{C}_{3}, \mathrm{C}_{4}$ or $\mathrm{C}_{6}$ alkan-2-sulphates, very feeble activity with $\mathrm{C}_{8}$ and $\mathrm{C}_{10}$ homologues, and increasing activity from $\mathrm{C}_{12}$ to $\mathrm{C}_{16}$. Symmetrical and near-symmetrical alkyl sulphates (substrates of the $\mathrm{S} 3$ enzyme) and primary alkyl sulphates, all tested in combination with tetradecan-2-ol plus pyruvate, failed to induce significant amounts of $\mathrm{S} 3$ enzyme even at elevated concentrations. Critical micelle concentrations were measured for alkan-2-sulphates and correlated with coinducer capacity and with the concentration dependence of induction by tetradecan-2-sulphate, which followed a hyperbolic saturation curve with $K_{\text {co-inducer }}=0.29 \mathrm{mM}$ (inducer concentration giving half-maximum induction). Successful induction was also achieved with tetradecan-2sulphate alone (no alcohol added), but only in the absence of pyruvate, under which circumstances hydrolysis of tetradecan-2-sulphate to the parent alcohol occurred as a prerequisite to bacterial growth. The collective results suggested that induction required not only a combination of secondary alcohol and long-chain alkan-2-sulphate in appropriate amounts (concerted induction), but also that their presence was required at a particular time, when the cells were actively growing and dividing.

\section{INTRODUCTION}

Pseudomonas $\mathrm{C12B}$ is a detergent-degrading soil bacterium that was isolated for its ability to grow on sodium dodecyl sulphate (SDS). Grown in batch culture on nutrient broth the organism produces one primary alkylsulphatase enzyme (designated $\mathrm{P} 1$ and acting on primary alkyl sulphates of chain-length $C_{6}$ or greater) and two secondary alkylsulphatases (designated $\mathrm{S} 1$ and

\footnotetext{
$†$ Present address: Pharmaceutical Research Laboratory, Upjohn Limited, Fleming Way, Crawley, Sussex, UK. UK.

$\ddagger$ Present address: Department of Medicine. University of Wales College of Medicine, Heath Park, Cardiff,
}

Abbreviation: CMC, critical micelle concentration. 
S2 acting respectively on D- and L-alkan-2-sulphates of chain-length $\mathrm{C}_{6}$ or greater). When a primary alkyl sulphate such as SDS is also present an additional primary alkylsulphatase appears (designated P2), whilst when Oronite (a commercial surfactant mixture containing $\mathrm{C}_{10^{-}}$ $\mathrm{C}_{22}$ secondary alkyl sulphates) is substituted for SDS a fifth enzyme (a secondary alkylsulphatase designated S3 and acting on symmetrical and near-symmetrical secondary alkyl sulphates) is also produced (see Dodgson et al., 1982 and Dodgson \& White, 1983, for reviews).

In early studies (Dodgson et al., 1974) on the induction of the S3 enzyme in cells grown on nutrient broth it was established that the Oronite sample used contained free secondary alcohols in addition to secondary alkyl sulphates. Separation of the two types of compound led to the discovery that neither would induce the S3 enzyme in the absence of the other. It was subsequently shown that any combination of alcohol and sulphate ester from tetradecan-2-ol, hexadecan-2-ol, tetradecan-2-sulphate and hexadecan-2-sulphate, led to the appearance of the enzyme. Individual compounds were ineffective. This requirement for a two-component system for the induction of an enzyme is apparently not unique and two other bacterial enzyme systems, each requiring two inducers, have since been reported (Blackwell \& Turner, 1978; MandredBerthelot et al., 1977).

Interest in the induction of the $\mathrm{S} 3$ secondary alkylsulphatase has been revived as a result of the findings (Matcham \& Dodgson, 1977) that the methods used by Dodgson et al. (1974) for the preparation of secondary alkyl sulphates lead to chain migration of the ester sulphate group, so that the probability existed that preparations of tetradecan-2- and hexadecan-2-sulphates used in earlier work contained other positional isomers as impurities. Later studies have shown that the $\mathrm{S} 3$ enzyme exhibits only relatively feeble activity towards alkan-2-sulphates and then only towards the L-forms of the stereoisomers (Shaw et al., 1980), adding further point to the possibility that induction of the enzyme might reflect impurity of inducer components in the earlier experiments.

Development of a more sensitive enzyme assay procedure, together with new methods for the preparation of alkan-2-sulphates that allow retention of configuration and do not cause sulphate group migration (Matcham \& Dodgson, 1977; White et al., 1980), have now permitted a more detailed study of factors influencing the induction of the S3 enzyme.

\section{METHODS}

Preparation of sulphate esters. Potassium salts of primary alkyl sulphates were prepared from corresponding primary alcohols (Dodgson et al., 1974), and potassium salts of secondary alkyl sulphate esters were prepared from secondary alcohols by the pyridine- $\mathrm{SO}_{3}$ method (Matcham \& Dodgson, 1977) or the triethylamine- $\mathrm{SO}_{3}$ method (White et al., 1980). Alcohols were purchased from Aldrich, K and K Rare and Fine Chemicals (Kodak), Fluka (Fluorochem), BDH and Koch-Light.

In addition to preparation by normal methods, samples of the potassium salts of 'tetradecan-2-sulphate' and 'decan-5-sulphate' were also prepared by the procedure of Dodgson et al. (1974). Quotation marks are used to designate these particular preparations because similar samples were used in the original study of S3 enzyme induction and, as indicated earlier, the method allows chain migration of the sulphate group. All sulphates esters were characterized by elemental analysis and, with the exception of 'tetradecan-2-sulphate' and 'decan-5sulphate', by infra-red (see Lloyd et al., 1961) and proton NMR spectroscopy (see White et al., 1980).

Solvolysis and purity of tetradecan-2-sulphate samples. Samples $(5 \mathrm{mg})$ of DL-tetradecan-2-sulphate (method of White et al., 1980) and 'DL-tetradecan-2-sulphate' (method of Dodgson et al., 1974) were each refluxed in $2 \mathrm{ml}$ of a dioxane/water mixture $(99: 1, \mathrm{v} / \mathrm{v})$ for $20 \mathrm{~min}$. Water $(8 \mathrm{ml})$ was added to the cooled solvolysate and the liberated alcohol(s) was extracted with $3 \times 4 \mathrm{ml}$ portions of diethyl ether. Pooled ether extracts were washed with $2.5 \mathrm{ml}$ of water, dried over anhydrous $\mathrm{Na}_{2} \mathrm{SO}_{4}$ and evaporated in a stream of air to a volume of about $1 \mathrm{ml}$. Samples (1$10 \mu \mathrm{l})$ of concentrated extracts were examined by gas-liquid chromatography (Perkin-Elmer F11 gas chromatograph, flame ionization detector). The column $(3 \mathrm{~mm} \times 3 \mathrm{~m})$ was packed with $20 \%$ Carbowax 1540 on Chromosorb W-AW DCMS and operated at $150{ }^{\circ} \mathrm{C}$. Tetradecan-2-ol standards were dissolved in diethyl ether before being applied to the column.

Organism. Pseudomonas C12B (Payne \& Feisal, 1963) was maintained on nutrient agar slopes and grown in batch culture at $30{ }^{\circ} \mathrm{C}$ (with shaking at 100 r.p.m.) on nutrient broth or on basal salts (Fitzgerald \& Payne, 1972) supplemented with $1 \mathrm{mM}-\mathrm{Na}_{2} \mathrm{SO}_{4}$ and a carbon suurce. Growth on broth and on basal salts media was monitored by measuring the optical density at $600 \mathrm{~nm}$ and $420 \mathrm{~nm}$ respectively. Growth media were sterilized by autoclaving for $15 \mathrm{~min}$ at $0.1 \mathrm{MPa}$. Alkyl sulphates were dissolved in sterile basal salts medium and sterilized by Millipore 
filtration (GS $0 \cdot 22 \mu \mathrm{m}$ filter) before adding aseptically to bulk sterile media. Alcohols of chain length greater than $\mathrm{C}_{8}$ were added to media before sterilization, whilst those of lower chain length were added aseptically after autoclaving the media. Media containing lower alcohols were incubated at $30^{\circ} \mathrm{C}$ for $5 \mathrm{~d}$ before inoculation in order to check for contamination. No contamination was ever noted.

Harvesting and treatment of cells. Broth-grown cells were harvested by centrifuging, resuspended in $10 \mathrm{~mm}$ Tris/ $\mathrm{HCl}$ buffer, $\mathrm{pH} \mathrm{7.5}$, and disrupted by sonication $(2 \mathrm{~min}$ at $90 \mathrm{~W}$, pulsed $50 \%$ duty cycle, Branson Ultrasonic generator and converter). Cell debris was removed by centrifuging at $4{ }^{\circ} \mathrm{C}$ and the supernatant was dialysed against two changes $(4 \mathrm{~h}$, then overnight) of $10 \mathrm{~mm}-\mathrm{Tris} / \mathrm{HCl}$ buffer, $\mathrm{pH} 7 \cdot 5$, before assaying for $\mathrm{S} 3$ alkylsulphatase activity and protein.

Similar methodology was applied to cells grown on supplemented basal saits media, except that culture media were sometimes retained and dialysed against the usual buffer before assaying for protein and the S3 enzyme. Samples of undialysed basal salts culture media were occasionally examined for residual alkyl sulphate surfactant.

In experiments designed to study the effects of varying the components of the inducer mixture on enzyme production, the following procedure was adopted after preliminary investigations which revealed that leakage of enzyme into culture media occurred under some conditions. No account was taken of this problem in the original studies of Dodgson et al. (1974). Erlenmeyer flasks $(250 \mathrm{ml})$ containing $50 \mathrm{ml}$ basal salts medium supplemented with sodium pyruvate $(1 \%, \mathrm{w} / \mathrm{v})$, alcohols and/or alkyl sulphates were inoculated with $50 \mu \mathrm{l}$ of an $18 \mathrm{~h}$ broth-grown culture of Pseudomonas C12B. Growth of the main culture was for $21 \mathrm{~h}$ (stationary phase coinciding with maximum $\mathrm{S} 3$ production) when $2 \mathrm{ml}$ samples were removed for assay. Samples were sonicated without separation of cells, so that total enzyme content of cells plus medium was obtained. Cell debris was removed by centrifuging at $4{ }^{\circ} \mathrm{C}$ and supernatants were dialysed as usual.

When measurements of residual surfactant in the growth media were required, cells were removed from culture samples $(1 \mathrm{ml})$ by centrifuging and surfactant measurements made on $0.5 \mathrm{ml}$ of the undialysed supernatant. Occasionally, $10 \mathrm{ml}$ samples were taken for gel zymography but samples were sonicated (as described earlier but for $3 \mathrm{~min}$ ), cell debris was removed by centrifuging, and the supernatant concentrated tenfold before use (immersible CX ultrafilter, nominal $M_{\mathrm{r}}$ limit 10000, Millipore).

Resting cell suspensions. Pseudomonas $\mathrm{C12B}$ was grown in batch culture in $400 \mathrm{ml}$ portions of nutrient broth until onset of the stationary phase. Cultures were pooled and mixed and $200 \mathrm{ml}$ portions were centrifuged in individual centrifuge pots for $20 \mathrm{~min}$ at $10000 \mathrm{~g}$ and $4{ }^{\circ} \mathrm{C}$. Each pellet was washed by resuspension in $20 \mathrm{ml}$ basal salts medium before recentrifuging. Each washed pellet was resuspended in $10 \mathrm{ml}$ sterile basal salts medium containing potassium DL-tetradecan-2-sulphate and DL-tetradecan-2-ol (each at final concentrations of 1, 5 and $10 \mathrm{mM}$ in different experiments) and the whole shaken at $30^{\circ} \mathrm{C}$ for $4,6,8$ or $10 \mathrm{~h}$. Zero controls consisted of suspension/inducer mixtures frozen at zero time, and a further control involved shaking the cell suspension in the absence of inducer and then transferring it to a flask containing the inducers and freezing immediately. Thawed cell suspensions were ruptured, centrifuged to remove debris and assayed for S3 activity.

Assay of S3 alkylsulphatase activity and protein concentration. In the earlier experiments of Dodgson et al. (1974), the symmetrical alkyl sulphate potassium pentan-3-sulphate was used as assay substrate for the S3 enzyme. However, relatively low activity is exhibited towards this substrate and substitution of a higher homologue, potassium nonan-5-sulphate, has enabled much greater sensitivity to be achieved (Shaw et al., 1980). The $\mathrm{BaCl}_{2}$ /gelatin method of Dodgson (1961) as modified by Thomas \& Tudball (1967) was used to measure $\mathrm{SO}_{4}^{2-}$ ions liberated enzymically from the substrate $(15 \mathrm{mM})$ in the presence of $0.1 \mathrm{M}$-Tris/ $\mathrm{HCl}$ buffer, $\mathrm{pH} 7.5$ (Shaw et al., 1980). A unit of enzyme activity is defined as the amount of enzyme catalysing release of $1 \mu \mathrm{mol} \mathrm{SO}{ }_{4}^{2-}(\mathrm{min})^{-1}$.

Protein concentration of samples was determined by the method of Lowry with bovine serum albumin (Fraction $\mathrm{V}$, Sigma) as standard.

Determination of surfactant concentration. Some alkyl sulphates tested as inducers were surfactants and sometimes their disappearance from cultures was monitored by a modification of the methylene blue method of Hsu (1965). After removing cells by centrifuging, a portion $(0.5 \mathrm{ml})$ of supernatant was mixed with an equal volume of an aqueous $1 \%(\mathrm{w} / \mathrm{v})$ solution of methylene blue and the whole was shaken with $1.0 \mathrm{ml}$ chloroform. The mixture was allowed to separate into two layers before removing $0.1 \mathrm{ml}$ of the chloroform layer and adding to $0.9 \mathrm{ml}$ of the same solvent. The absorbance of the blue solution was measured at $590 \mathrm{~nm}$ against a chloroform blank. A separate calibration curve was necessary for each surfactant, standard solutions being prepared in basal salts medium containing $1 \%(\mathrm{w} / \mathrm{v})$ sodium pyruvate.

Determination of tetradecan-2-ol. In some experiments liberation of tetradecan-2-ol in cultures containing tetradecan-2-sulphate was monitored by GLC. Culture samples $(2.5 \mathrm{ml})$ were supplemented with hexadecan-2-ol $(50 \mu \mathrm{g}$ in $10 \mu \mathrm{l}$ methanol $)$ as internal standard, and extracted with redistilled hexane $(3 \times 1 \mathrm{ml})$. Pooled extracts were evaporated under $N_{2}$ and the residues dissolved in $40 \mu \mathrm{l}$ dry light petroleum (b.p. $\left.60-80{ }^{\circ} \mathrm{C}\right)$. Samples $(7 \mu \mathrm{l})$ were analysed in a Perkin-Elmer 8310 gas chromatograph (flame ionization detector) fitted with a $10 \%$ Carbowax $20 \mathrm{M}$ on $80 / 100$ Supelcoport column $(2 \mathrm{~m} \times 2 \mathrm{~mm})$ operated at $200^{\circ} \mathrm{C}$. Amounts of tetradecan-2-ol were estimated from integrated peak areas by comparison with the internal standard. 
Critical micelle concentrations (CMC). The Rhodamine 6G method (Carey \& Small, 1969) was used to determine $\mathrm{CMC}$ values for alkan-2-sulphates of chain-length $\mathrm{C}_{10}$ and greater. Determinations were done under conditions appropriate to the induction experiments, i.e. at $30^{\circ} \mathrm{C}$ in the presence of basal salts-pyruvate alone or supplemented with $1 \mathrm{mM}$-DL-tetradecan-2-ol.

Gel electrophoresis and zymography. Polyacrylamide gel electrophoresis was done as described by Payne et al. (1974) and S1, S2 and S3 alkylsulphatase activities were detected by incubating extruded gels with 'potassium decan-5-sulphate'. All three enzymes attack this impure racemic substrate and activity is revealed by appearance of white bands due to the production of highly insoluble decanol isomers (see Dodgson \& White, 1983).

\section{RESULTS}

\section{Purity of tetradecan-2-sulphate in relation to enzyme induction}

The possibility was mentioned earlier that $\mathrm{S} 3$ induction by any combination of alcohol and sulphate ester from tetradecan-2-ol, hexadecan-2-ol, 'tetradecan-2-sulphate' and 'hexadecan-2sulphate', may reflect the presence in the alkyl sulphate preparation of positional isomers arising from sulphate group migration during chemical synthesis. Because the S3 enzyme exhibits only feeble activity towards alkan-2-sulphates (and then only towards L-forms) it was reasonable to ask whether the true alkyl sulphate inducer component was a positional isomer with superior properties as a substrate. Solvolysis of 'DL-tetradecan-2-sulphate' (prepared by the method of Dodgson et al., 1974) and of DL-tetradecan-2-sulphate (method of White et al., 1980), followed by GLC of the light petroleum-extracted alcohols, established that the former preparation contained a major and a minor impurity (both with lower retention times than tetradecan-2-ol), together accounting for about $30 \%$ of the preparation. Only tetradecan-2-ol was present in the solvolysis extracts obtained from the ester prepared according to White et al. (1980). No attempt was made to identify the impurities.

Both sulphate ester preparations (at $1 \mathrm{~mm}$ concentration in combination with $1 \mathrm{~mm}$ tetradecan-2-ol) were able to induce $\mathbf{S} 3$ enzyme but neither could serve as inducer in the absence of tetradecan-2-ol; tetradecan-2-ol alone was equally ineffective. Clearly induction depends on the presence of a sulphate group at C-2 and not positional isomer impurities.

\section{Disappearance of surfactant and appearance of S3 enzyme during growth}

The exponential phase of growth of Pseudomonas $\mathrm{C12B}$ on basal salts medium containing $1 \mathrm{mM}$-DL-tetradecan-2-ol and the same concentration of either 'potassium DL-tetradecan-2sulphate' or the corresponding pure sulphate ester, was accompanied by disappearance of the ester from the medium. This is considered to reflect the presence of the two secondary alkylsulphatases, S1 and S2 (detected by gel zymography), which are respectively specific for Dand L-alkan-2-sulphates. The S3 enzyme appeared in cells early in the exponential growth phase but, as time proceeded, more enzyme was present in the medium (up to $45 \%$ of the total activity). This may reflect leakage arising from the presence of surfactant rather than active secretion of enzyme. Unfortunately (see later), $\mathrm{S} 3$ induction always required the presence of one of a group of sulphate esters, all of which were surfactants.

\section{Attempts to induce the $S 3$ enzyme in resting-cell suspensions}

Resting cell suspensions of Pseudomonas C12B had previously been used to study the induction of the $\mathbf{P} 2$ primary alkylsulphatase by primary alkyl sulphates and alkane sulphonates (Cloves et al., 1980). However, attempts to induce the S3 enzyme by shaking resting cell suspensions, for up to $10 \mathrm{~h}$, with combinations of DL-tetradecan-2-sulphate and DL-tetradecan-2ol at concentrations of 1,5 or $10 \mathrm{~mm}$, were unsuccessful.

\section{Effect on induction of varying the alcohol component}

Alkan-2-ols. Racemic alkan-2-ols (nominally $1 \mathrm{mM}$ in basal salts/pyruvate medium) of different chain lengths were substituted for racemic tetradecan-2-ol in the alcohol/sulphate ester inducer mixture, with DL-tetradecan-2-sulphate $(1 \mathrm{mM})$ as the sulphate ester component. The higher alcohols are relatively insoluble in aqueous media, and the true solution concentration is likely to be less than the nominal $1 \mathrm{mM}$. Culture optical densities $(1 \cdot 70 \pm 0 \cdot 15$, Cecil CE 292 


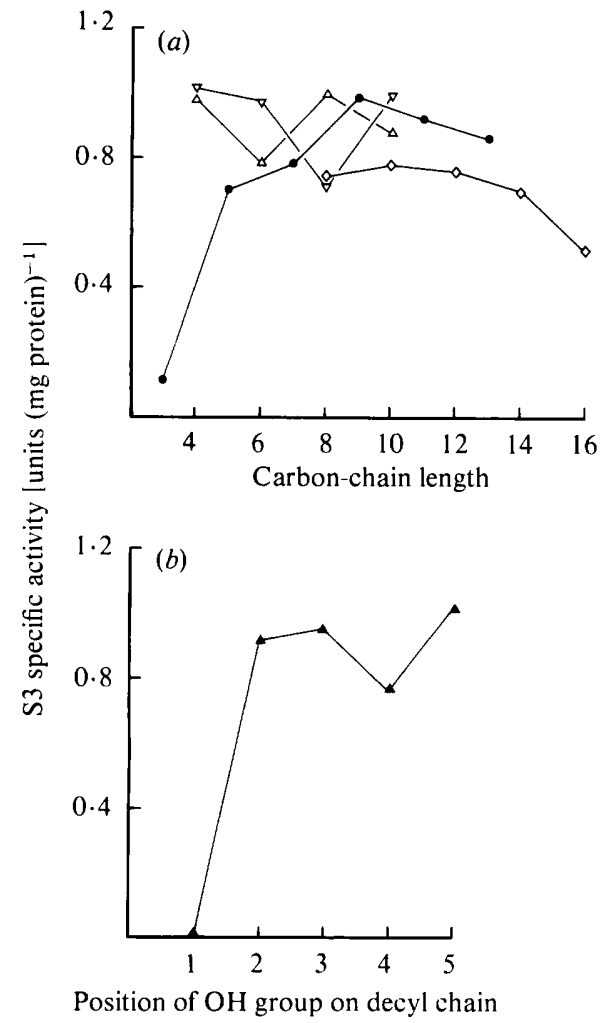

Fig. 1. Effect of varying the alcohol co-inducer on induction of S3 alkylsulphatase. Enzyme activity was measured in sonicated whole-culture fluids after growth $(24 \mathrm{~h})$ on $1 \%$ pyruvate-basal salts containing $1 \mathrm{~mm}$-DL-tetradecan-2-sulphate and $1 \mathrm{~mm}$-alcohol. (a) $\Delta, \diamond, \nabla$, Alkan-2-ols of various chain length (different symbols represent experiments done on separate occasions); $\bigcirc$, symmetrical secondary alcohols of various chain length. (b) Effect of decanol isomers on S3 enzyme induction.

spectrophotometer, $1 \mathrm{~cm}$ path length) and $\mathrm{pH}$ values $(7 \cdot 8 \pm 0 \cdot 2)$ after $21 \mathrm{~h}$ were constant for all inducer systems tested. Figure $1 a$ shows that alkan-2-ols ranging from $C_{4}$ to $C_{16}$ served as excellent co-inducers. No induction occurred in the absence of either the alcohol or sulphate ester component. It will be seen later that a short-chain alkan-2-sulphate such as DL-butan-2sulphate did not serve as a co-inducer in association with DL-tetradecan-2-ol. However, the possibility existed that it might be effective in association with some alcohol of different chain length. In fact, DL-butan-2-sulphate $(1 \mathrm{mM})$ failed to act as a co-inducer with an equimolar concentration of any alkan-2-ols in the range $C_{4}$ to $C_{16}$.

Symmetrical secondary alcohols. Propan-2-ol (simultaneously a symmetrical alcohol and an alkan-2-ol) served only as a relatively poor co-inducer. However, higher homologues were effective (Fig. 1a), but again both components of the inducer mixture had to be present for induction to occur.

Primary alcohols. No induction of the S3 alkylsulphatase occurred with ethanol, hexanol, decanol and tetradecanol, each in combination with DL-tetradecan-2-sulphate.

Induction by decanol isomers. The effect on induction of moving the hydroxyl group along the alkyl chain was examined with the decanol series (Fig. 1b). As expected, decan-1-ol was without effect but good induction was observed with racemic secondary isomers, irrespective of whether the hydroxyl group was present at C-2, C-3, C-4 or C-5.

Loss of tetradecan-2-sulphate from the medium. In cases where induction of $\mathrm{S} 3$ enzyme activity occurred, substantial amounts of tetradecan-2-sulphate $(>75 \%)$ disappeared from the medium. Variable but less extensive loss of the ester occurred in those cases where induction was slight or absent. 


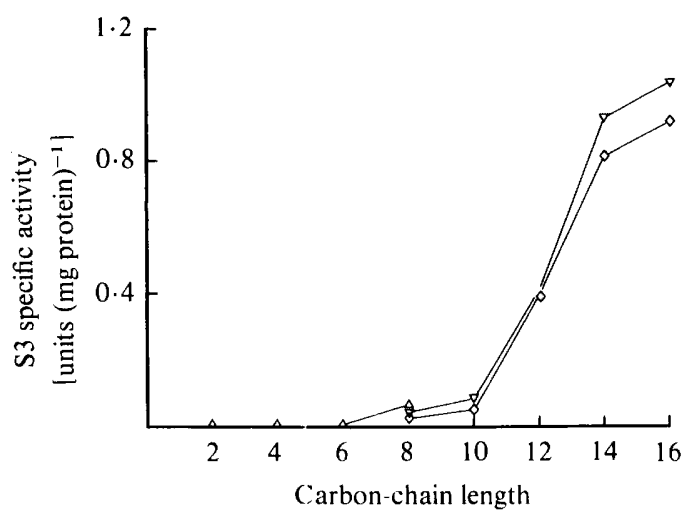

Fig. 2. Effect of varying the chain length of alkan-2-sulphate co-inducers on induction of S3 alkylsulphatase. Enzyme activity was measured in sonicated whole-culture fluids after growth $(24 \mathrm{~h})$ on $1 \%$ pyruvate-basal salts containing $1 \mathrm{~mm}$-1)L-tetradecan-2-ol and $1 \mathrm{~mm}$-alkan-2-sulphate. Different symbols represent experiments done on separate occasions.

\section{Effect on induction of varying the sulphate ester component}

Alkan-2-sulphate chain length. Racemic alkan-2-sulphates of increasing chain length were tested (at $1 \mathrm{~mm}$ concentration) as co-inducers in cells growing on basal salts/pyruvate medium containing $1 \mathrm{mM}$-DL-tetradecan-2-ol. The extent of growth of Pseudomonas C12B and the culture $\mathrm{pH}$ were generally unaffected by changing the sulphate ester co-inducer. No enzyme activity was obtained with $\mathrm{C}_{4}$ and $\mathrm{C}_{6}$ esters (Fig. 2), very feeble activity with $\mathrm{C}_{8}$ and $\mathrm{C}_{10}$ and then increasing activity from $\mathrm{C}_{12}$ to $\mathrm{C}_{16}$. When the sulphate esters were tested in association with a short-chain alcohol (DL-butan-2-ol; $1 \mathrm{mM}$ ), DL-tetradecan-2-sulphate proved to be the only effective co-inducer.

Symmetrical alkyl sulphates. The S3 enzyme can hydrolyse symmetrical alkyl sulphates of chain length $\mathrm{C}_{5}$ or greater (Shaw et al., 1980) and it was possible that such compounds might serve as co-inducers of the enzyme. However, none of the compounds tried $\left(C_{3}, C_{5}, C_{7}, C_{9}, C_{11}\right.$ and $\left.\mathrm{C}_{13}\right)$ in combination with tetradecan-2-ol led to the appearance of significant amounts of enzyme activity, although it was detectable for the longer-chain $\left(>\mathrm{C}_{7}\right)$ compounds $(<0.1$ units $\mathrm{mg}^{-1}$; cf. about 1 unit $\mathrm{mg}^{-1}$ for active inducers).

Primary alkyl sulphates. The range of sulphates tested involved even-numbered-chain compounds from $\mathrm{C}_{2}$ to $\mathrm{C}_{16}$ but all failed to co-induce significant $\mathrm{S} 3$ enzyme activity.

Induction by octyl sulphate isomers. Whereas octan-1-sulphate did not serve as an effective coinducer, DL-octan-2-sulphate co-induced weak S3 enzyme activity (see Fig. 2). DL-Octan-3sulphate was about as effective as the 2-sulphate whilst DL-octan-4-sulphate was ineffective.

Effect of DL-tetradecan-2-sulphate concentration. Increasing the initial concentration of DLtetradecan-2-sulphate (from 0.05 to $1.5 \mathrm{~mm}$ ) in the presence of $1 \mathrm{mM}$-DL-tetradecan-2-ol revealed a saturation phenomenon analogous to that exhibited by an enzyme towards increasing concentrations of substrate. The $K_{\text {co-inducer }}$ value (analogous to $K_{\mathrm{m}}$, see Cloves et al., 1980) for the effect, estimated by the direct linear plot of Eisenthal \& Cornish-Bowden (1974) was $0.29 \mathrm{~mm}$. Not too much significance can be placed on the value obtained because of the tendency of the sulphate ester concentration to diminish during the growth period. However, it seems high for an induction phenomenon alone and it may reflect other processes such as transport or enzymic conversion.

Effects of concentration of other sulphate esters. The dependence of induction on ester concentration, coupled with the loss of sulphate ester co-inducer from the medium, raised the possibility that a sulphate ester such as DL-octan-2-sulphate (a weak co-inducer at $1 \mathrm{~mm}$ concentration) might serve as a better co-inducer at high concentrations. Induction experiments 
Table 1. Induction of $S 3$ alkylsulphatase by various sulphate esters each in combination with its parent alcohol

\section{Alcohol*}

Butan-2-ol

Octan-2-ol

Tetradecan-2-ol

Hexadecan-2-ol

Octadecan-2-ol

Octan-1-ol

Undecan-6-ol
Sulphate ester*

Butan-2-sulphate

Octan-2-sulphate

Tetradecan-2-sulphate

Hexadecan-2-sulphate

Octadecan-2-sulphate

Octan-1-sulphate

Undecan-6-sulphate
S3 Specific activity (units $\mathrm{mg}^{-1}$ )

0
$0 \cdot 04$
$0 \cdot 80$
$0 \cdot 81$
0
0
0

* Alcohol and sulphate esters were present initially at $1 \mathrm{~mm}$ concentrations in $1 \%(\mathrm{w} / \mathrm{v})$ sodium pyruvate-basal salts medium. See text for details.

were therefore done (in the presence of $1 \mathrm{mM}$-DL-tetradecan-2-ol) in which the concentration of DL-octan-2-sulphate was increased within the range 1 to $8 \mathrm{~mm}$. The overall eightfold increase in concentration enhanced the very poor enzyme production seen at $1 \mathrm{~mm}$ concentration by some $56 \%$, with about $37 \%$ of the ester sulphate still remaining at the end of the growth period. When this experiment was repeated, but substituting primary octyl sulphate, very weak enzyme activity was observed at the higher concentrations, with about $8 \%$ of the ester remaining intact at the highest concentrations.

Undecan-6-sulphate (1 mM) was an extremely poor co-inducer in the presence of $1 \mathrm{mM}$-DLtetradecan-2-ol; doubling or halving the ester concentration did not significantly increase the amount of enzyme produced. More than $60 \%$ of the ester remained at the end of the growth period.

Effects of pairing alcohols with sulphate esters. Because the pairing of tetradecan-2-sulphate with its parent alcohol gave rise to high levels of $\$ 3$ activity, the effects of other pairings of ester and parent alcohol (each at $1 \mathrm{~mm}$ ) were examined (Table 1). Such a pairing had no special significance in the induction process.

\section{Growth on DL-tetradecan-2-sulphate}

Good growth of Pseudomonas C12B was obtained on basal salts supplemented with $0.1 \%$ $(\mathrm{w} / \mathrm{v})$ tetradecan-2-sulphate $(3 \mathrm{mM})$ alone, although there was a long lag period of about $20 \mathrm{~h}$ (Fig. $3 a$ ). Growth was accompanied by disappearance of tetradecan-2-sulphate and a transient accumulation of tetradecan-2-ol during the exponential growth phase. Stationary phase cells, grown under identical conditions in separate experiments, contained appreciable amounts of S3 enzyme $\left(0.8\right.$ units $\left.\mathrm{mg}^{-1}\right)$. In a parallel experiment in which the ester was supplemented with sodium pyruvate $(1 \%, w / v)$, the ester remained intact throughout the culture cycle and there was no production of tetradecan-2-ol (Fig. $3 b$ ).

\section{Critical micelle concentrations}

CMC values obtained for alkan-2-sulphates in basal salts medium supplemented with sodium pyruvate $(1 \%, \mathrm{w} / \mathrm{v})$ and DL-tetradecan-2-ol $(1 \mathrm{mM})$ were as follows: DL-decan-2-sulphate, $8.1 \mathrm{mM}$; DL-dodecan-2-sulphate, $0.98 \mathrm{mM}$; DL-tridecan-2-sulphate, $0.19 \mathrm{mM}$, DL-tetradecan-2sulphate, $0.049 \mathrm{mM}$; DL-hexadecan-2-sulphate, $0.023 \mathrm{~mm}$. Only those esters with chain lengths greater than $C_{10}$ were effective surfactants; this should be seen in the light of the fact (Fig. 2) that the $C_{8}$ and $C_{10}$ alkan-2-sulphates exhibited only feeble co-inducer ability. 

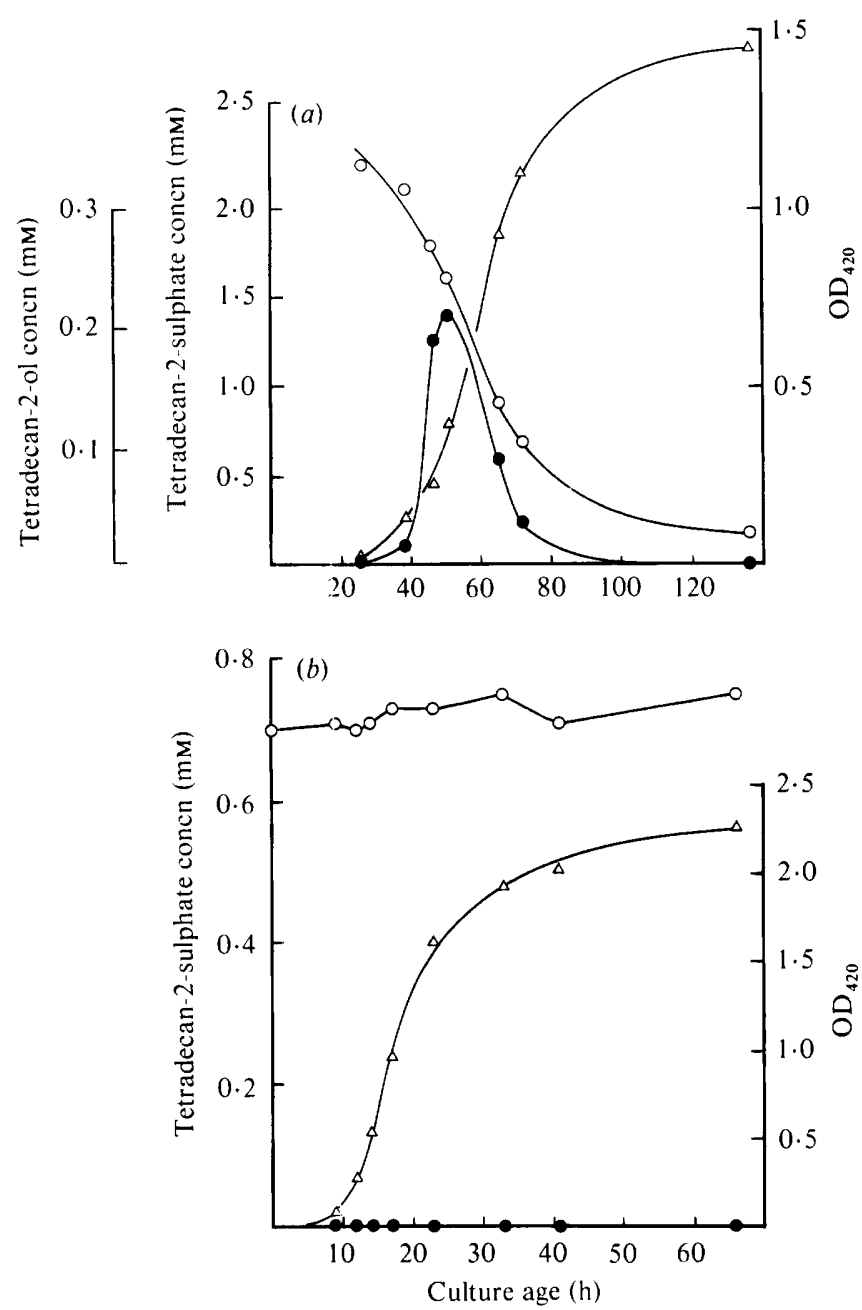

Fig. 3. Hydrolysis of tetradecan-2-sulphate to tetradecan-2-ol during growth of Pseudomonas C12B. Growth in basal salts medium containing $(a) 0.1 \%(\mathrm{w} / \mathrm{v})$ tetradecan-2-sulphate as sole carbon source, $(b)$ $1 \%(\mathrm{w} / \mathrm{v})$ sodium pyruvate and $1 \mathrm{~mm}$-tetradecan-2-sulphate. Culture optical densities $(\triangle)$ were monitored at $420 \mathrm{~nm}$ using a Pye Unicam SP6-550 spectrophotometer. Assays for tetradecan-2sulphate $(O)$ and tetradecan-2-ol $(\bigcirc)$ are described in the text. In $(b)$, tetradecan-2-ol concentrations were all $<4 \mu \mathrm{M}$.

\section{DISCUSSION}

This work has confirmed and extended previous findings (Dodgson et al., 1974) that induction of the $\mathrm{S} 3$ secondary alkylsulphatase requires two components when Pseudomonas C12B is grown on nutrient broth or on other carbon sources such as pyruvate. One component must be $\mathrm{a}_{4}$ to $\mathrm{C}_{16}$ secondary alcohol, the position of the hydroxyl group on the chain apparently being immaterial; even symmetrical secondary alcohols are effective co-inducers. In contrast, primary alcohols are not effective, although they can certainly enter the cells because the organism grows on many of the primary alcohols tested in the present study (Payne, 1963; Rigby et al., 1986). Presumably therefore, failure to serve as co-inducer does not reflect transport problems and perhaps reflects the inability of a primary alcohol (or its metabolites) to bind in an appropriate manner to some component at gene level. On the other hand, the wide range of secondary alcohols that can serve as co-inducers must throw doubt on the concept of a highly specific binding phenomenon. Interestingly, Pseudomonas $\mathrm{C12B}$ when grown on nutrient broth possesses alcohol dehydrogenase activity towards primary alcohols and D-alkan-2-ols only. 
However, growth on certain secondary alcohols leads to the production of alcohol dehydrogenase activity towards L-alkan-2-ols and other positional isomers including symmetrical isomers (Rigby et al., 1986). Perhaps the production of S3 alkylsulphatase depends on initial induction of such alcohol dehydrogenase activity, although the converse is clearly not true.

The second component (sulphate ester) required to induce the $\mathrm{S} 3$ enzyme is much more closely defined than the first. Indeed, when the associated alcohol is DL-butan-2-ol, only the $C_{14}$ alkan2-sulphate is apparently effective. When DL-tetradecan-2-ol is the associated alcohol DLhexadecan-2-sulphate appears to be equally as effective as the $\mathrm{C}_{14}$ ester, whilst esters with shorter chains become increasingly less effective until the $C_{8}$ ester produces very weak enzyme activity only. Symmetrical isomers of secondary alkyl sulphates are ineffective, as are primary alkyl sulphates. The effects of moving the sulphate group to positions other than $\mathrm{C}-1, \mathrm{C}-2$ and the symmetrical position cannot be stated with any degree of certainty, but experiments with the octane series indicated that movement of the sulphate group away from the C-2 position served only to reduce the feeble co-inducer activity further.

The co-inducer, tetradecan-2-sulphate, is a surfactant, and its low CMC value $(0.049 \mathrm{~mm})$ would ensure that the concentration of molecules in non-micellar form would have been extremely low in the experiments described earlier. The surfactant properties may be responsible for the leakage of $\mathrm{S} 3$ enzyme from cell to culture medium, particularly as the enzyme appears to be localized in the cell wall (Dodgson et al., 1978). Predominance of the micellar form of tetradecan-2-sulphate in the growth medium may also mean that some of the associated alcohol co-inducer was incorporated into the micelles.

Ability to form micelles decreases with decreasing alkyl chain length and it may be significant that only in the cases of the $\mathrm{C}_{12}, \mathrm{C}_{13}, \mathrm{C}_{14}$ and $\mathrm{C}_{16}$ alkan-2-sulphates (i.e. good inducers) were $\mathrm{CMC}$ values exceeded at concentrations used in the induction experiments. This raises the possibility that tetradecan-2-sulphate merely serves in a surfactant capacity, perhaps allowing for more effective uptake of the true inducer or inducer precursor, the secondary alcohol. However, this is unlikely as other effective surfactants (e.g. SDS and its $\mathrm{C}_{14}$ homologue) are not co-inducers.

Growth of the bacterium on DL-tetradecan-2-sulphate alone led to production of the S3 enzyme. Under these conditions the ester was the sole carbon source, and enzymic liberation of alcohol is to be anticipated as a prerequisite for growth. This was confirmed in separate experiments (Fig. $3 a$ ) which showed transient formation of tetradecan-2-ol during exponential phase. Simultaneous presence of both ester and alcohol for a brief period during exponential phase was evidently sufficient to induce the $S 3$ enzyme. However, when the growth medium contained tetradecan-2-sulphate and pyruvate (conditions known to be insufficient for induction), hydrolysis of the ester did not occur and no tetradecan-2-ol was detected. Under these conditions growth must occur at the expense of pyruvate and enzymic hydrolysis of the ester to alcohol was unnecessary, leading to the observed failure to induce S3 synthesis. While confirming the requirement for the simultaneous presence of ester and alcohol coinducers, these experiments also indicate that cells must be exposed to inducers while in the exponential phase, if induction is to occur. Support for this comes from the failure to induce the enzyme when suspensions of resting cells, harvested at the onset of the stationary phase, are shaken with the usual DL-tetradecan-2-sulphate/DL-tetradecan-2-ol inducer mixture.

Hydrolysis of DL-tetradecan-2-sulphate is achieved by the S1 and S2 alkylsulphatases, specific for D- and L-alkan-2-sulphates respectively. Hitherto these enzymes have been regarded as constitutive (Dodgson et al., 1982) and appearing in stationary phase (Fitzgerald \& Laslie, 1975). Assignment of both these characteristics will now need to be reviewed because pyruvate appears to repress synthesis (no hydrolysis of tetradecan-2-sulphate, Fig. 3b), and under certain conditions (e.g. Fig. $3 a$ ) enzymic hydrolysis occurred in exponential phase.

Perhaps the greatest significance of the present work is to bring into prominence the need for two inducers to be present for the production of the S3 enzyme. The initial discovery of this phenomenon (Dodgson et al., 1974) passed largely unnoticed, as have the two other examples that have since emerged. In one of those cases, a $\beta$-glucuronidase produced by Escherichia coli, both glucuronic acid and the parent glucuronide are required (Mandrand-Berthelot et al., 1977). 
In the other case, Blackwell \& Turner (1978) have shown that induction of the ethanolamine ammonia lyase of $E$. coli requires the co-presence of ethanolamine and coenzyme $\mathrm{B}_{12}\left(5^{\prime}\right.$ deoxyadenosylcobalamin); the term 'concerted induction' was coined to describe the phenomenon. It seems not unreasonable to ask whether these three examples merely represent the tip of the iceberg and that the phenomenon of a 'concerted induction' may be much more common than would appear at present.

We wish to thank Mr I. Dalvies and Mr O. R. Thomas of this Department for technical assistance, and the Department of Chemistry, University College Cardiff for performing the elemental and NMR analyses.

\section{REFERENCES}

Blackwell, C. M. L. \& Turner, J. M. (1978). Microbial metabolism of amino alcohols: formation of co-enzyme $B_{12}$-dependent ethanolamine ammonia-lyase and its concerted induction in Escherichia cali. Biochemical Journal 76, 751-757.

Carey, M. C. \& Small, D. M. (1969). Micellar properties of dihydroxy and trihydroxy bile salts: effects of counterion and temperature. Journal of Colloid and Interface Science 31, 382-396.

Cloves, J. M., Dodgson, K. S., White, G. F. \& FitzGerald, J. W. (1980). Specificity of P2 primary alkylsulphohydrolase induction in the detergentdegrading bacterium Pseudomonas C12B. Biochemical Journal 185, 13-21

DodGson, K. S. (1961). Determination of inorganic sulphate in studies on the enzymic and non-enzymic hydrolysis of carbohydrate and other sulphate esters. Biochemical Journal 78. 312-319.

Dodgson, K. S. \& White, G. F. (1983). Some enzymes involved in the microbial degradation of sulphated surfactants. In Topics in Enzyme and Fermentation Biotechnology, vol. 7, pp. 90-155. Edited by A. Wiseman. Chichester: Ellis Horwood.

Dodgson, K. S., Fitzgerald, J. W. \& Payne, W. J. (1974). Chemically defined inducers of alkylsulphatases present in Pseudomonas C12B. Biochemical Journal 138, 53-62.

Dodgson, K. S., Fitzgerald, J. W. \& Payne, W. J. (1978). Localization of the $\mathrm{S} 3$ secondary alkylsulphohydrolase of Pseudomonas C12B. FEMS Microbiology Letters 3, 115-117.

Dodgson, K. S., White, G. F. \& Fitzgerald, J. W. (1982). Sulfatases of Microbial Origin, vols $1 \& 2$. Boca Raton, USA : CRC Press.

EISENTHAL, R. S. \& CORNISH-Bowden, A. (1974). The direct linear plot. A new graphical procedure for estimating enzyme kinetic parameters. Biochemical Journal 139, 715-720

Fitzgerald, J. W. \& Laslie, W. W. (1975). Loss of primary alkylsulfatase and secondary alkylsulfatases (S-1 and S-2) from Pseudomonas C12B: effect of culture conditions, cell-washing procedures, and osmotic shock. Canadian Journal of Microbiology 21, 59-68.

Fitzgerald, J. W. \& Payne, W. J. (1972). Induction in a Pseudomonas species of sulphatases active on short chain alkylsulphates. Microbios 5, 87-100.
Hsu, Y.-C. (1965). Detergent-splitting enzyme from Pseudomonas. Nature, London 207, 385-388.

Lloyd, A. G., Tudball, N. \& Dodgson, K. S. (1961). Infra-red studies on sulphate esters. III. $O$-sulphate esters of alcohols, amino alcohols and hydroxylated amino acids. Biochimica et biophysica acta 52, 413419.

MandRand-Berthelot, M.-A., Novel, G. \& Novel, M. (1977). L'induction gratuite de la $\beta$-glucuronidase d'Escherichia coli $\mathrm{K} 12$ et son double mecanisme de repression. Biochimie 59, 163-170.

Matcham, G. W. J. \& Dodgson, K. S. (1977). Preparation and characterization of substrates suitable for the study of stereospecific secondary alkylsulphohydrolases of detergent-degrading microorganisms. Biochemical Journal 167, 717-722.

PAYNe, W. J. (1963). Pure culture studies of the degradation of detergent compounds. Biotechnology and Bioengineering 5, 355-365.

PAYNe, W. J. \& FeISAL, V. E. (1963). Bacterial utilization of dodecyl sulfate and dodecyl benzene sulfonate. Applied Microbiology 11, 339-344.

Payne, W. J., Fitzgerald, J. W. \& Dodgson, K. S. (1974). Methods for visualization of enzymes in polyacrylamide gels. Applied Microbiology 27, 154158.

Rigby, D. J., Dodgson, K. S. \& White, G. F. (1986). Utilization of primary and secondary alcohols by the detergent-degrading bacterium Pseudomonas C12B. Journal of General Microbiology 132, 35-42.

Shaw, D. J., Dodgson, K. S. \& White, G. F. (1980). Substrate specificity and other properties of the inducible S3 secondary alkylsulphohydrolase purified from the detergent-degrading bacterium Pseudomonas C12B. Biochemical Journal 187, 181196.

Thomas, J. H. \& Tudball, N. (1967). Studies in the enzymic degradation of $\mathrm{L}$-serine $O$-sulphate by a rat liver preparation. Biochemical Journal 105, 467-472.

White, G. F., Lillis, V. \& Shaw, D. J. (1980). An improved procedure for the preparation of alkyl sulphate esters suitable for the study of secondary alkylsulphohydrolase enzymes. Biochemical Journal 187, 191-196. 